\title{
À PROCURA DA IDENTIDADE NACIONAL, O FUTEBOL É ABSORVIDO COMO POLÍTICA DE ESTADO (1930-1945)
}

Agnaldo Kupper ${ }^{1}$

Recebido em: 14/07/2020

Aprovado em: 19/10/2020

RESUMO: O futebol, enquanto prática, foi introduzido no Brasil por setores privilegiados da sociedade. Popularizou-se nas primeiras décadas do século XX. A partir da década de 1930, o Estado brasileiro, sob o comando de Getúlio Vargas, conteve as mobilizações reivindicatórias promovidas pelos trabalhadores ao enquadrar tanto a classe operária quanto a burguesia industrial em seu discurso "policlassista" Para tanto, não desprezou o esporte que virou mania nacional. Muito ao contrário: utilizou-o como instrumento para a legitimação do regime estadonovista (1937-1945) na busca de alicerces nacionalistas.

Palavras-chave: Estadonovismo; Getúlio Vargas; futebol; identidade nacional; Brasil.

\section{EN BÚSQUEDA DE LA IDENTIDAD NACIONAL, EL FÚTBOL SE ABSORBE COMO POLÍTICA DE ESTADO (1930-1945)}

RESUMEN: El fútbol, como práctica, fue introducido en Brasil por sectores privilegiados del sociedad. Se hizo popular en las primeras décadas del siglo XX. A partir de la década de 1930, el estado brasileño, al mando de Getúlio Vargas, contuvo las movilizaciones de demanda promovido por los trabajadores enmarcando tanto a la clase obrera como a la burguesía industrialista en su discurso "policlasista". Por eso, no despreció el deporte que se convirtió en una locura nacional. Todo lo contrario: lo utilizó como instrumento de legitimidad del régimen Estado Novo (1937-1945) em busca de fundamentos nacionalistas.

Palabras llave: Estadonovismo; Getulio Vargas; fútbol; identidad nacional; Brasil.

\section{IN SEARCH OF NATIONAL IDENTITY, FOOTBALL IS ABSORBED AS A STATE POLICY (1930-1945)}

ABSTRACT: Football, as a practice, was introduced in Brazil by privileged sectors of society. It became popular in the first decades of the 20th century. From the 1930s onwards, the Brazilian State, under the command of Getúlio Vargas, restrained the demands for mobilization promoted by the workers by framing both the working class and the industrial bourgeoisie in their "polyclassist" discourse. Therefore, he did not despise the sport that became a national

\footnotetext{
${ }^{1}$ Doutor na área de História e Sociedade (Unesp). Escritor. E-mail: agnaldokupper2009@ @otmail.com. ORCID: https://orcid.org/0000-0001-7547-2334.
} 
craze. Quite the contrary: he used it as an instrument to legitimize the state regime (1937-1945) in the search for nationalist foundations.

Keywords: Estadonovismo; Getúlio Vargas; soccer; national identity; Brazil.

\section{Futebol no Brasil: breve trajetória}

O futebol emergiu elitista. Na Primeira República (1889-1930), popularizou-se espetacularmente, acompanhando as transformações brasileiras, em especial a partir da década de 1910, quando a prática foi absorvida por populares e por empreendimentos fabris.

O futebol de fábrica surgiu como entretenimento e lazer. Aos poucos, outros interesses brotaram, com empresários descobrindo na prática a possibilidade de se obter disciplina e controle sobre o tempo dos trabalhadores, além do cerceamento sobre as atividades dos mesmos nos sindicatos, da valorização de seus produtos e artigos, da visualização positiva da empresa patrocinadora, da imagem de preocupação com a condição física e de lazer de seus subalternos. No entanto, não se pode afirmar que o futebol desmobilizou as lutas políticas operárias (KUPPER, 2019).

A busca de patrocinadores para a prática - caso dos primeiros clubes operários que buscaram no patrão subsídios - também aponta para uma tendência do brasileiro: a de se sentir protegido e de depender de quem considera superior.

O fenômeno, mesmo sem intenções, estruturou os pilares para Getúlio Vargas que, durante o período do Estado Novo (1937-1945), estabeleceu algo que sentia carente: uma identidade nacional. E o futebol foi elemento bem utilizado para tanto. Mas Vargas só pode fazê-lo porque já havia a incorporação do esporte pelo operariado e por populares enquanto prática e apreciação. Ou seja, Vargas apropriou-se do futebol que, por sua vez, já fervia no sangue popular, aproveitando-se do apoio à prática dado por diversos empresários, como que usurpando de uma política regional, local, o que significa dizer que, ao procurar controlar a vida operária, Getúlio Vargas incorporou o que os trabalhadores já carregavam no seu cotidiano, apenas projetando essa modalidade esportiva em termos nacionais, fortalecendo, dessa forma, elos, em especial a partir dos eventos mundiais denominados Copas do Mundo.

Afinal, para quê e para quem serviu e serve o futebol? Como esta prática enraizou-se tão violentamente na alma do povo brasileiro a ponto de ver seus dias transformados após uma conquista ou indivíduos trajarem-se como se fizessem parte do elenco de uma agremiação ou de torcedores zombarem do derrotado desprezando as hierarquias sociais? Mais: o que está por trás do jogo, além do jogo em si? 
A análise historiográfica concede-nos pistas de que a trajetória da popularização do futebol no Brasil permite que entendamos a relação entre as ações sociais, políticas e econômicas. Isto não significa que se almeja reduzir a prática do futebol a essas esferas. Cada ciência é particular por delimitar um campo de pesquisa com problemáticas, objetos e métodos próprios. Porém, por vezes, a complexidade de alguns objetos de conhecimento exige que ciências se unam e componham estudos interdisciplinares ou transdisciplinares. Nesse sentido, para atingir os objetivos deste trabalho foram analisados jornais, atas, balancetes e periódicos diversos, utilizando-os como fontes. Mais: a identificação da trajetória de muitas personalidades envolvidas com o futebol exigiu o cruzamento de dados, tal qual uma investigação jornalística. Isso porque faz-se necessário entender como o brasileiro apropriou-se do esporte, como que o tomando das camadas mais abastadas que o introduziram no país. Mesmo com as tentativas das elites em coibir a prática, a apropriação se deu e teria sido utilizada como forma de desviar atenções para as lutas operárias das primeiras décadas republicanas brasileiras para posteriormente ser apropriado como um dos objetos de edificação do Estado Varguista (19301945), particularmente durante o período do Estado Novo (1937-1945), período em que Getúlio Vargas abandonou os princípios do liberalismo econômico e passou a regulamentar todas as atividades produtivas do país, tornando o Estado a principal fonte de investimentos diretos. Para Euclides de Freitas a associação entre a popularização do futebol como manifestação cultural e esportiva e o Estado, fez com que o esporte passasse, no contexto de Copas do Mundo, a ser visto como metas de governo (COUTO, 2014). Mas não só, uma vez que a base de sustentação para os objetivos varguistas esteve nas estruturas clubistas e a análise de atas e estatutos de diversas estruturas de futebol demonstram que muitas agremiações obtiveram apoio estatal, caso do Canto do Rio Futebol Clube, fundado em 1913 na cidade de Niterói em bases populares e intenções de lazer, embora seu principal nome histórico seja Ernani Amaral Peixoto, interventor federal do Estado do Rio de Janeiro entre 1937 e 1939, casado com Alzira Vargas (filha de Getúlio e Darci Vargas), e do Palmeiras Futebol Clube de São João da Boa Vista, São Paulo, que estruturou-se com apoio do governo varguista e que teve em Getúlio Vargas Filho seu grande apoiador que, inclusive, veio a ocupar o posto de presidente da Federação Paulista de Futebol em 1943.

A popularização dos esportes - entre os quais o futebol que, em tempos contemporâneos, abandona progressivamente seu caráter recreativo para transformar-se em atividade vinculada ao consumo de massa - fundamentou-se (não só, mas acima de tudo) em relações capitalistas.

Segundo Bero Rigauer (1969), o esporte é uma adaptação à vida moderna, consistindo 
como forma dissimulada para o trabalho, reproduzindo, em si, o mundo do capitalismo por ter em sua constituição autoridade, concorrência, competência, aperfeiçoamento, organização e burocracia.

Vários autores apontam como causas da proliferação dos esportes modernos (caso, em especial, do futebol) fatores como o nacionalismo, interesses científicos e a cultura de massa. Porém, o destaque à popularização do futebol também deve ser atribuído à facilidade de praticálo, como bem define Glauco Souza (2015, p. 46):

De maneiras diversas, as classes baixas também puderam desfrutar do esporte bretão, pois o futebol, diferentemente do remo, do turfe, do ciclismo ou do alpinismo, não era refém de instrumentos para ser praticado, isto é, enquanto, sobretudo o remo e o turfe, precisavam, obrigatoriamente, de barcos e cavalos, o futebol não exigia nem mesmo uma bola oficial.

$\mathrm{Na}$ busca do entendimento de como o futebol foi utilizado simbolicamente na construção da identidade nacional durante os anos 1930 e 1940, (SOUZA, 2002, p.28) aponta para uma diferenciação na visão de nação entre os agentes envolvidos: para os trabalhadores o futebol estaria ligado ao lazer; para o Estado, ao mundo do trabalho.

Meses antes da Revolução de 1930, o Brasil participou da primeira Copa do Mundo, realizada no Uruguai entre os dias 13 e 30 de julho. O time brasileiro caiu na fase de grupos com apenas dois pontos somados (fato que teria sido comemorado pelos paulistas, como que desejando o revés), vencendo uma partida e perdendo outra. No geral, o país ficou em sexto lugar entre treze selecionados. A ausência de unidade entre as diversas regiões do país ficou clara através do desempenho.

Ainda em 1930, ao assumir a presidência da República após um processo visto por muitos como revolucionário, Getúlio Vargas apresentou o que intitulou "Programa de Reconstrução Nacional”. Entre as medidas apontadas no documento - dos dezessete tópicos elencados - um referia-se ao futebol: a regulamentação da profissão de atleta da prática. Dessa forma, o governo varguista (1930-1945), a fim de promover e incentivar o esporte, criou instituições organizadoras de eventos que acabaram por se tornar importantes veículos de propaganda do governo e de seu regime político. Em 1931, o futebol foi inserido na legislação trabalhista. A intenção foi a de tratar os jogadores de futebol como trabalhadores que, como os demais, poderiam atuar em prol do país, edificando-o unitariamente. Dois anos depois, o governo Vargas criou a profissão do jogador de futebol obrigando-o - como a todo trabalhador assalariado - à sindicalização. Tal profissionalização correspondia a um movimento cultural e político amplo, envolvendo os interesses da disciplina social do Estado. 
Para Franco Júnior (2007, p.78) ao assumir o poder em 1930, Getúlio Vargas teria percebido o quanto o futebol detinha o poder de mobilizar as massas e como a seleção brasileira poderia agir como um símbolo catalisador da nacionalidade almejada. A percepção de Vargas teria se definido quando, em 1932, o Brasil venceu torneio de futebol disputado no Uruguai (Copa Rio Branco) e os jogadores foram recebidos como heróis no Rio de Janeiro, então capital federal.

Mas nem tudo foi fácil no caminho perseguido por Getúlio Vargas na busca da unificação do país e da criação de uma identidade nacional. A Revolução Constitucionalista de 1932 expôs a tensão brasileira entre um mundo novo em fase não consolidada. Trouxe reflexos ao futebol brasileiro, uma vez que aflorou, ainda mais, a rivalidade os Estados do Rio de Janeiro e de São Paulo, os dois grandes centros da prática à época. Os esportistas paulistas apoiaram a revolta, inclusive o jogador Arthur Friedenreich, referência como atleta, que lutou pelas causas de São Paulo e, por conta do processo, doou troféus e medalhas para a causa paulista, além de participar do movimento como sargento e tenente. Vale lembrar, ainda, segundo estimativas incertas, que sessenta clubes de futebol de São Paulo e do interior cederam esportistas para a luta paulista contra o governo provisório de Getúlio Vargas, totalizando perto de mil e quatrocentos combatentes. Friedenreich, juntamente com o Estado de São Paulo como um todo, foi derrotado por Getúlio, talvez num único momento em que quem perdeu, acabou, de certa forma, ganhando, uma vez que o governo getulista teria obtido freios em suas intenções.

A segunda Copa do Mundo foi realizada na Itália fascista de Benito Mussolini, no mesmo ano em que foi promulgada a Carta Constitucional brasileira. As discussões sobre a convocação de jogadores profissionais e amadores para a Copa de 1934 acirraram-se através da mídia esportiva da época (em especial pelo Jornal do Brasil, defensor do amadorismo, e pelo Jornal dos Sports, defensor do profissionalismo pleno no futebol brasileiro). As divergências foram responsáveis pela participação considerada negativa do Brasil na Copa italiana. A seleção brasileira não foi representada pelos seus melhores jogadores devido à continuidade das péssimas relações entre as associações do Rio de Janeiro e de São Paulo, embora Getúlio Vargas tenha feito esforços para unir os principais centros de futebol do país. Nesta segunda edição de Copa do Mundo, a seleção brasileira teve como chefe da delegação Lourival Fontes, um dos mais próximos colaboradores de Getúlio Vargas. O próprio presidente tratou de colocar o futebol dentro do palácio do governo, quando afirmou que "a missão do time não é somente de caráter esportivo, mas envolve o desempenho de um dever cívico" (NEGREIROS, 1979, p.217), talvez inspirado por Benito Mussolini, que transformara o Mundial de então em evento para consolidar o regime fascista. 
A vencedora da segunda edição de Copa futebolística foi a Itália, com o Brasil terminando em décimo terceiro lugar. A ausência de unidade no selecionado brasileiro teria demonstrado a falta de integridade nacional. Mas não só. Além da ausência dos melhores jogadores do país e as disputas entre dirigentes, as condições de viagem e a ausência de uma preparação física adequada ocasionaram a péssima participação brasileira. O país ainda não apontava para uma política de uso do esporte como triunfo de unidade nacional. Porém, fazêlo, era uma questão de tempo.

O jornal O Diário de S. Paulo assim se posicionou diante da campanha brasileira na Copa de 1934:

(...) Representada por uma seleção muito abaixo das suas possibilidades, o Brasil viu-se desclassificado, logo na primeira partida que jogou. Repetiu-se assim, uma vez mais, a triste sina que nos tem sido reservada, nas grandes competições internacionais de esporte, para os quais não nos faltam elementos eficazes de representação, principalmente em se tratando de futebol. Mas, a eterna imprevidência, a reiterada desídia, agora assim é a ocasião de afirmálo, a falta de visão e de patriotismo dos dirigentes não permitiram que desempenhássemos o papel, que a justo título, pelo valor dos nossos jogadores, poderíamos ter desempenhado. (...) em última análise, mesmo com a derrota, aliás prevista, o selecionado não fracassou totalmente e soube perder com brio. Valha-nos isso, como consoladora atenuante. E valha também, para o futuro, aos dirigentes do nosso esporte, mais esta rude lição. (DIÁRIO S. PAULO, 29 DE MAIO DE 1934)

\section{Estado Novo e a identidade nacional}

O Estado Novo (1937-1945), sob o comando de Getúlio Vargas, marcou, definitivamente, a transição de uma sociedade eminentemente agrária para uma sociedade urbano-industrial. Durante o regime, ideais conservadores, autoritários e nacionais foram elaborados, com o Estado colocando-se acima dos interesses de classes, embora os setores econômicos governassem de fato (CARONE, 1977, p.113). Segundo Ângela de Castro Gomes (1980), a fase da história brasileira que vai de 1930 a 1937 foi marcada por continuidades e descontinuidades políticas, sendo marca do período a instabilidade edificada em choques entre as diversas forças sociais que disputavam um espaço político no cenário nacional, como o inconformismo paulista marcado pelo processo revolucionário de 1932 e a resistência do sindicalismo livre, marcado pelos debates parlamentares e por conspirações militares, indicativos do que viria a ser estabelecido ao final de 1937: o regime do Estado Novo.

A política geral de industrialização e a própria modernização empreendida pelo Estado não foi uma vitória de um dinâmico setor urbano e não nasceu das fábricas. Foi uma política emergente dos níveis supraestruturais, ou seja, de cima para baixo. 
O Estado Novo (1937-1940) procurou mitificar a nação através da exaltação das qualidades do governo e comemorando as ações públicas. Segundo Francisco Weffort, o populismo estadonovista teve início a partir da crise do liberalismo oligárquico brasileiro, aproximando as classes populares e camadas médias urbanas dos setores industriais (GOMES, 2001, p.75).

No aspecto social, o estadonovismo procurou criar a imagem de plena harmonia entre população e governo, utilizando-se de dispositivos jurídicos que asseguravam a repressão aos movimentos de oposição, enquanto a aliança com as massas urbanas estruturou-se no conjunto da legislação trabalhista e na manipulação política propiciada por mecanismos de propaganda estatal, fazendo concreta a ideologia do trabalhismo e representando o atrelamento dos trabalhadores e de suas organizações às diretrizes políticas implementadas por Vargas.

Neste sentido, o Estado Novo procurou mitificar a nação através da exaltação das qualidades do governo e comemorando as ações públicas. Para Helena Bomeny,

O grande projeto político a ser materializado no Estado Novo, iniciado com a Revolução de 1930, tinha como núcleo central a construção da nacionalidade e a valorização da brasilidade, o que vale dizer, a afirmação da identidade nacional brasileira (...) Estava em questão a identidade do trabalhador, a construção de um homem novo para um Estado que se pretendia novo (...) Ambicioso e extenso, o projeto estadonovista deveria orientar todas as iniciativas do Estado dirigidas à sua própria construção e à construção da sociedade.(BOMENY, 1999, p.51)

Numa cerimônia cívica, em dezembro de 1937 (mês seguinte à instalação do Estado Novo), o Presidente assistiu à queima e destruição das bandeiras estaduais e ao hasteamento do pavilhão nacional na capital federal, Rio de Janeiro, em clara manifestação de superação do Estado Oligárquico, substituído pelo agora Estado Populista.

Ao procurar construir a imagem de uma nação consentânea, o Estado Novo procurou mascarar os conflitos sociais existentes entre os diferentes segmentos sociais do país. Ou seja, para o regime, a desordem, o individualismo e a indisciplina deveriam ser superados pela sociedade brasileira em prol dos interesses e dos ideais da nação. $\mathrm{O}$ futebol, enquanto exemplo, serviria ao propósito.

O discurso nacionalista brasileiro foi disseminado, inclusive através da manipulação e regulação estatal sobre veículos de comunicação, com o intuito de se estabelecer unidade para o exercício do poder do Estado. Imagens de Getúlio Vargas e das Forças Armadas dominaram até mesmo a produção cinematográfica durante o regime: ao reverenciar Getúlio, a onipresença do líder; no caso das Forças Armadas, a segurança. Mas não só. Através do Departamento de Imprensa e Propaganda (criado em 27 de dezembro de 1939), a exaltação do Primeiro de Maio, 
do Sete de Setembro, dos aniversários de Getúlio e das façanhas do futebol que, enquanto esporte de massas, tornou-se um elemento catalisador de tal sentimento. Para tanto, o Estado passou a fazer uso da exaltação de conquistas, caso do futebol e seus triunfos.

$\mathrm{Na}$ tentativa de fazer do Brasil um território congregado, independentemente das diferenças sociais e econômicas da população, Vargas passou a construir uma "arquitetura desportiva" através do erguimento de praças esportivas, colônias de férias, clubes e escolas de Educação Física voltadas para a juventude do país (em 1937 foi introduzida a obrigatoriedade da Educação Física enquanto disciplina nas escolas), para o operariado e descendentes e para menores habitantes de cortiços e favelas.

A oficialização do futebol enquanto esporte no Brasil se deu através do Decreto-Lei n. 526, de 1 de Julho de 1938, que criou o Conselho Nacional de Cultura, vinculado ao Ministério da Educação e da Saúde. Nas intenções governamentais, deve ser destacada a importância da imprensa, então um dos principais veículos de formação da opinião pública, que procurou atender aos interesses estatais e adaptar-se ao gosto do leitor para o aumento de suas vendas.

Outra iniciativa do Estado Novo foi a criação do Conselho Nacional dos Desportos (1941), também vinculado ao Ministério da Educação e Saúde. A missão do CND seria a de orientar, fiscalizar e incentivar a prática de desportos no país, podendo autorizar ou desautorizar a participação brasileira em disputas internacionais, além de vigiar as atividades profissionais esportivas. O mesmo decreto estruturou as confederações por ramo esportivo (basquetebol, pugilismo, vela e motor, esgrima, xadrez e a Confederação Brasileira de Desportos, responsável pelo futebol, saltos, natação, remo, voleibol, handball, tênis, atletismo e polo-aquático). O destaque da CBD, no entanto, seria o futebol, de acordo com o II Parágrafo do decreto mencionado.

Outra prática estatal utilizada para o engrandecimento definitivo do futebol enquanto esporte nacional foi o estímulo à construção de estádios (caso do Pacaembu, na cidade de São Paulo, inaugurado em 1940). Tais estruturas incutiriam entre os brasileiros as representações oficiais, a integração nacional e o sentimento patriótico.

Desta forma, através do futebol o Estado passou a produzir a transição da "memória coletiva" para a "memória nacional" (ALABARCES, 2002, p. 48). Ou seja, na Era Vargas o esporte em questão - até então vinculado ao lazer e controle - ganhou importância de Estado, procurando estabelecer a visão de que ricos, pobres, trabalhadores, brancos, negros e mulatos deveriam ter direito à participação do contexto geral nacional. A mensagem estava dada: da montagem de um clube de bairro à estruturação do selecionado nacional, o imaginário de nação deveria estar presente, estabelecendo-se o sentimento de pertencimento. 
Até 1938, as vitórias brasileiras em torneios internacionais foram assim dispostas: 1914 - Copa Roca (torneio contra a Argentina); 1919 - campeonato sul-americano; 1922 campeonato sul-americano; Copa Roca; Taça Rodrigues Alves (contra o Paraguai); 1923 Taça Brasil-Argentina; 1931 - Taça Rio Branco (torneio contra o Uruguai); 1932 - Taça Rio Branco. O vice-campeonato obtido pelo Brasil no Sul-americano de 1936-1937 (disputado na Argentina e com vitória da seleção anfitriã) foi munição para as pretensões de Getúlio Vargas, que procurou exaltar a união e civilidade brasileira e condenar a violência argentina. Para tanto, sua voz foi o Jornal dos Sports, que intitulou o jogo final daquele campeonato como o "jogo da vergonha":

O match de ontem à noite caracterizou-se por uma violência que não se pode descrever em todos os seus detalhes. Para vencer o esquadrão do Brasil, o scracht argentino empregou o máximo de violência, o que resultou em um conflito de grandes proporções. Os rapazes do Brasil se portaram galhardamente. Ameaçados pelos adversários que usaram mais as travas das chuteiras do que o futebol limpo (...) (JORNAL DOS SPORTS, 02 DE FEVEREIRO DE 1937)

De qualquer forma, a recepção aos jogadores nacionais foi manifestada entusiasticamente pelo programa radiofônico A Hora do Brasil, como também por outros diários:

(...) Nesse momento era incalculável a multidão que se aglomerava na praça Mauá. (...) Assim, Adhemar desceu, fê-lo nos braços dos torcedores que o carregavam em triunfo. Também Roberto, Tim e Afonsinho apareceram nos braços da multidão.(...) Em seguida, o sr. Luis Aranha cedeu a palavra ao chefe da delegação brasileira, sr. Castello Branco, que agradecendo as carinhosas homenagens que se prestavam aos jogadores, ressalta que o feliz êxito obtido pela representação se devia à disciplina, patriotismo e perfeita compreensão esportiva de todos os seus componentes. (O ESTADO DE S. PAULO, 07 DE FEVEREIRO DE 1937)

Mesmo derrotada, a seleção brasileira foi recepcionada por torcedores na Praça Mauá, com direito a salvas de canhão e hino nacional executado por uma banda militar. Uma demonstração de que o pretendido nacionalismo pretendido estava no caminho correto.

No esforço da construção do Estado Nacional, Vargas procurou associar ação política com identificação através do futebol, utilizando a prática para garantir o apoio dos brasileiros à estrutura do Estado Novo, como o fez através da campanha brasileira na Copa de 1938, realizada na França, vinculando as vitórias da seleção às vitórias da nação.

Para o evento, o governo federal estadonovista procurou tomar medidas que dessem unidade à organização do futebol no país, como atesta $O$ Estado de S. Paulo: 
Os jornais noticiaram que o chefe do governo provisório estava disposto a interferir na contenda entre a Confederação de Desportos e a Federação Brasileira de Futebol a fim de evitar o fracasso da representação no segundo campeonato mundial [1934], a disputar-se nos estádios italianos. Informariam ainda os mesmos jornais que seriam chamados para uma conferência, os srs. Luiz Aranha e Arnaldo Guinle, os dois esportistas mais em evidência naquelas duas entidades esportivas (...) Representou a Confederação em todos os tempos, os elementos esportivos do país? Nem sempre. Nela dominaram oligarquias de clubes regionalistas, que trataram de defender, como era natural, os seus interesses particulares, ou de satisfazer as possíveis vaidades ou ambições de seus diretores.(O ESTADO DE S. PAULO, 02 DE FEVEREIRO DE 1938)

Para o torneio, como forma de demonstrar a importância da participação brasileira, Getúlio enviou sua filha, Alzira Vargas. E mais: concedeu à delegação brasileira uma subvenção de 200.000\$000 (CORREIO DA MANHÃ, 08 DE JUNHO DE 1938). Também foi realizada a "Campanha do Selo", com objetivo de arrecadar fundos para a Confederação Brasileira de Desportos (CBD), além dos recursos disponibilizados pelo governo federal. Também através da imprensa, conclamou-se ao empresariado ajuda à seleção brasileira para que mais recursos fossem disponibilizados para uma possível campanha vitoriosa nacional em solo francês:

A "Campanha do Selo", a tão bem inspirada iniciativa, teve um sucesso invulgar, ao se iniciar há dias, no Rio. Está quase esgotada a emissão de 100 mil selos. Com essa campanha os afeiçoados podem se interessar diretamente pela viagem de nossa seleção, pois adquirindo um selo o "torcedor" faz sua fezinha de ir também à Taça do Mundo. É a sorte que designará o feliz afeiçoado que acompanhará a delegação. Melhor iniciativa para interessar os nossos afeiçoados não poderia surgir. Os que adquirissem o "selo cebedense" não só auxiliariam patrioticamente o comparecimento do Brasil na III Taça do Mundo como se tornarão, igualmente, candidatos a um lugar por 500 réis. (JORNAL A GAZETA, 06 DE ABRIL DE 1938).

A Copa do Mundo de 1938 teria marcado o encontro dos brasileiros consigo mesmo ou a intenção de fazê-lo, afinal foi a primeira vez que o país foi para um evento mundial com um time miscigenado (em 1930, só o negro Fausto; em 1934, apenas Leônidas da Silva). Ou seja, em 1938, o futebol teria emergido como representação social do brasileiro, quando se procurou instaurar "uma ordem que possibilitará às pessoas orientar-se em seu mundo material e social e controlá-lo; e, em segundo lugar, possibilitar que a comunicação seja possível entre os membros de uma comunidade" (MOSCOVICI, 2012, p.21).

Para uma boa campanha da seleção brasileira de 1938, foi traçado um planejamento rigoroso, através da mobilização de diferentes setores da sociedade civil, governo e imprensa especializada. Desta forma, um programa de treinamento físico foi elaborado pela Escola de 
Educação Física do Exército, jogos-treino foram agendados e a premiação aos atletas e comissão técnica foi previamente acertada, como pode ser observado nas palavras de Luiz Aranha, presidente da Confederação Brasileira de Desportes no período:

Os nossos esforços em proporcionar todo o conforto aos scratchmen terão de ser correspondidos à altura. Por isso exigimos disciplina, sem transigência, ao mesmo tempo que dedicação ao preparo físico. Sem a compreensão moral da missão, nenhum resultado prático se poderá esperar na cancha. (JORNAL DOS SPORTS, 16 MARÇO DE 1938).

A utilização da imprensa para que o evento fosse abraçado pelos brasileiros foi intensa, como demonstra trecho de matéria do jornal O Estado de S. Paulo:

[...] O Sr Alarico Maciel, chefe da concentração, enviará a São Paulo na hora do embarque a seguinte saudação: "A imprensa e o povo de São Paulo. Os jogadores da CBD concentrados em Caxambú, não podem partir para a Europa sem o estímulo, o applauso e o carinho do grande, nobre e generoso povo paulista. Elles vão a São Paulo nesse firme e honroso propósito, irmanados no mesmo ideal, num trabalho commum de elevar no estrangeiro o nome do Brasil unido, forte e feliz".(O ESTADO DE S. PAULO, 21 DE ABRIL DE 1938).

O Brasil passou a ser apontado pela imprensa como um dos favoritos para vencer a Copa de 1938. Mas ao que consta, não foi tudo como o imaginado e planejado. Antes mesmo de se apresentarem ao selecionado para o preparo para o torneio da França, Domingos da Guia, Fausto e Leônidas da Silva teriam se envolvido em uma polêmica quando da excursão do Flamengo à Bahia: no Cassino Casaris, Domingos teria agredido Fausto e Leônidas e desacatado autoridades policiais. Detido, da Guia foi libertado em seguida (JORNAL DOS SPORTS, 21 DE MARÇO DE 1938).

Para Melina Pardini (PARDINI, 2009), o regime estadonovista, na tentativa de passar e consolidar sua ideologia, passou a controlar a mídia. Para tanto, os jornais procuravam representar a massa torcedora como harmônica, apontando a ausência de conflitos entre as classes sociais. Ou seja, ao controlar rádios e jornais, Vargas procurou apresentar um futebol ordenado, coletivo e disciplinado. Para tanto, Leônidas da Silva (negro e individualista enquanto jogador) passou a ser apresentado de acordo com os valores desejados e almejados pelo Estado Novo. A popularidade de Leônidas teria sido utilizada por parte de agentes governamentais de Getúlio Vargas para exaltar a inserção de negros e mulatos na seleção do país, como símbolo da harmonia e democracia racial apregoada pelo Estado Novo (COSTA, 2006, p.107). No entanto, importante ressaltar que Leônidas da Silva não ficou conhecido apenas pela habilidade com a bola, mas também pelo envolvimento em polêmicas e pela 
indisciplina, embora seus problemas de comportamento extracampo tenham sido minimizados através da mídia controlada.

No jogo entre Brasil e Itália, em 16 de junho, lojas como o Mappin Store e a tradicional Casa Alemã fecharam suas portas. Mesmo a "sereia da Gazeta" (que tal como uma Igreja anunciava o meio-dia e, consequentemente, o horário de almoço), durante o evento, passou a não apenas anunciar a divisão do dia, mas os gols das partidas que envolveram a seleção brasileira.

Mas foi mesmo o rádio o veículo de comunicação mais utilizado: a Rádio Club do Brasil (PRA-3) realizou transmissões diretas da França das partidas que envolveram o selecionado brasileiro e emissoras radiofônicas paulistanas como a Cruzeiro do Sul, Cosmos e Clube do Brasil, através de alto-falantes, retransmitiram os jogos. Os cinemas projetavam os filmes das partidas do Brasil dois dias após de ocorridas, mesmo que incompletas (duração de cerca de meia hora). Nas transmissões, manifestações de patriotismo:

O dia do descobrimento do Brasil, feriado nacional, não passou despercebido pelos jogadores brasileiros que participarão de sensacional torneio da taça do mundo. A "Rádio Saudades do Brasil" dedicou uma hora à data. Leônidas [o Diamante Negro],diretor da estação improvisada, reuniu a rapaziada, convidou os dirigentes da delegação e fez uma hora de música brasileira. (...) Sugeria que toda a delegação cantasse, embora baixinho, o Hino Nacional. Repercutiu muito bem no Arlanza tal iniciativa do ponteiro do São Cristóvão, pois todo o mundo ficou sabendo que os cracks brasileiros chegarão a Paris, sabendo cantar direitinho a nossa música oficial.(JORNAL A NOITE, 06 DE MAIO DE 1938)

Até mesmo as prisões foram afetadas durante os jogos do Brasil na Copa francesa, uma vez que em dias de jogo os detidos disputavam proximidade junto aos aparelhos de rádio disponibilizado pelos agentes: "presos e carcereiros chegaram a se confraternizar a cada vitória do Brasil” (FAUSTO, 2009, p.146).

Próprio da comoção e expectativa sobre o torneio, a imprensa escrita e falada (rádio) chegou a propagandear acusações de que existiria um complô contra a seleção brasileira devido aos preconceitos dos dirigentes europeus e pela violência dos adversários aplicada sobre os jogadores brasileiros, principalmente a partir da peleja contra a Tchecoslováquia, denominada "batalha de Bordéus", quando dois jogadores de cada lado foram expulsos. As exclusões sumárias dos brasileiros teriam sido injustas e o árbitro teria marcado um pênalti inexistente em favor do adversário. Sobre a partida - que terminou empatada em 1 a 1 - o Estado de S. Paulo publicou:

Não somos propensos a explosões de entusiasmo porque não nos deixamos influenciar pelos arroubos sensacionalistas e cabotinos de algumas criaturas. 
Vamos, pois, comentar a frio o significado do que ocorreu anteontem no Estádio Municipal de Bordéus. (O ESTADO DE S. PAULO, 11 DE JUNHO DE 1938)

Independentemente das denúncias, parecia mesmo que o Brasil ganhava contornos de irracionalidade em torno do futebol. Após algumas partidas do selecionado brasileiro, nas ruas buzinaço, bandeiras brasileiras exibidas nos principais pontos comerciais e fábricas soando suas sirenas. A eliminação do selecionado brasileiro da final do torneio (após um pênalti cometido pelo zagueiro Domingos da Guia sobre o italiano Piola quando a bola estava fora de campo) frente à seleção anfitriã, fez o país sentir-se vítima dos países do velho continente, afinal, para a imprensa e os especialistas da época, individualmente o escrete brasileiro era melhor.

Novamente a Itália foi campeã, com o Brasil terminando em terceiro lugar após cinco jogos (três vitórias, um empate e uma derrota). Na decisão pelo terceiro lugar, o Brasil venceu a Suécia por 4 a 2 e o brasileiro Leônidas da Silva tornou-se o maior goleador do torneio com sete gols. A derrota da seleção brasileira para a italiana na Copa de 1938, especificamente em 16 de Junho, fez a população chafurdar em tristeza. Assim descreve Cid Pinheiro Cabral o que foi aquela partida pelas semifinais da III Copa do Mundo de Futebol realizada na França:

Com Leônidas e Domingos da Guia, aquele o goleador da III copa, o Brasil marcou seu primeiro lance de proeminência bem visível, no futebol mundial. Na semifinal, frente à Itália, perdeu de 2 x 1, com os italianos (logo depois campeões) valendo-se, para a obtenção do resultado positivo, de um pênalti de Domingos da Guia em Piola, o chamado 'pênalti da inocência', que só podia mesmo ser cometido por jogadores de um país onde as regras eram apenas propriedade dos árbitros e de um ou outro crítico. Bastante fustigado, durante o jogo, pelo centroavante Piola, Domingos da Guia, vendo a bola fora de jogo, resolveu investir contra seu corpo, na mais infantil das desforras. Pênalti e caminho aberto para a segunda conquista italiana consecutiva da Copa - que Mussolini exigira, ao despedir-se da equipe do seu país com um forte murro na mesa e mais do que um desejo, uma ordem: 'Sejam felizes e lembrem-se de que não defenderão apenas o futebol campeão do mundo, mas a própria honra da Itália'. Maneira de dizer de um bota-fora? Não, algo, sim, com todo o verniz de um ultimato! (CABRAL, 1978, p.37)

O resultado contra a Itália foi tido como injusto, como atestou Getúlio Vargas em suas anotações pessoais: “O jogo de football monopolizou as atenções. A perda do team brasileiro para o italiano causou uma grande decepção e tristeza no espírito público, como se tratasse de uma desgraça nacional" (VARGAS, 1995, p. 140).

Leônidas da Silva e Domingos da Guia (em que pese o pênalti cometido), tornaram-se, definitivamente, ídolos de todo um povo, contribuindo para que se encarnasse o valor ideológico da democracia racial de Gilberto Freyre. Leônidas passou a preencher páginas dos jornais, inaugurar lojas e tornou-se garoto propaganda até mesmo de pasta de dente e chocolate. 
Os jornais, submetidos ao Estado Novo, através de fotografias, procuraram tratar os jogadores brasileiros como heróis, apontando para os torcedores como patriotas passivos e entendedores de que os atletas fizeram o melhor que lhes era possível. Fato é que a Copa de 1938 teria alcançado seus objetivos, seja de utilizar o futebol para um projeto de união do país, seja para testar a imprensa e sua fidelidade ao regime.

As autoridades do Estado Novo não perderam a oportunidade de associar o sucesso da seleção ao regime estabelecido a partir de 1937, procurando fortalecer a ideia de identidade nacional, como que procurando consolidar a visão de nascimento do "novo homem brasileiro", marcado pelo civismo e patriotismo, características inseridas em um "Estado forte" a ser solidificado a partir do aperfeiçoamento físico de seus cidadãos através da educação física. Tanto que na década seguinte o Ministério da Educação passou a sugerir que o incentivo ao esporte entre os brasileiros, independentemente do estrato social do cidadão, poderia trazer ao brasileiro um aperfeiçoamento físico e, com ele, a projeção de um país moderno:

A política a que nos vimos subordinando, através de atos continuados de governo, parece indicar que o Brasil não pretende perder-se, no meio do mundo, mas deseja achar-se, dentro de si mesmo. Uma população de misturas não perturba a união nacional, apenas conduz o movimento de nossa civilização a lutas contraditórias, perdidas no meio de diretrizes e finalidades heterogêneas. (...) Bem avisada, a política que se ocupa de restaurar o caminho histórico, no curso do qual caldearemos a nossa própria raça e fortaleceremos os característicos que darão ao brasileiro personalidade própria. (...) A raça é ponto de partida para a definição de uma poderosa organização nacional. (LYRA FILHO, 1941, p.43-45)

A partir do desempenho da seleção brasileira na Copa de 1938, passou a ser fixada a ideia do futebol brasileiro como único e próprio de um estilo de vida. Um futebol-arte. Praticálo, passou a ser visto como um dever cívico. O historiador Plínio Negreiros defende que a participação brasileira na Copa de 1938 foi importante na construção da identidade nacional ao gerar comoção e mobilização popular, destacando que o fenômeno não seria possível sem a presença dos meios de comunicação:

Enfim, a participação brasileira na Copa de 38, em função de todo o clima que criou, mostrou que o futebol já havia adquirido um outro papel fundamental: articulador da unidade nacional. Esse poder do futebol foi muito bem utilizado pelo poder público, bastando que se olhe todo o emprenho demonstrado pelas mais diferentes autoridades brasileiras. Porém, também coube à imprensa uma função vital: os periódicos vivenciaram plenamente o clima de Copa do Mundo. Mais do que um meio de informação ou análise, os jornais optaram por animar o torcedor ou mesmo iludi-lo com um otimismo exagerado. $\mathrm{O}$ rádio, como grande novidade numa transmissão direta da Europa, também se mostrou fundamental. Não podemos esquecer do cinema, com suas reportagens. (NEGREIROS, 1997, P.227) 


\section{Considerações finais}

O futebol foi elemento muito bem utilizado pelo governo varguista para a criação de um símbolo de identidade nacional. Mas Vargas só pode fazê-lo porque já havia a incorporação do esporte pelo operariado e por populares enquanto prática e apreciação. Ou seja, Vargas apropriou-se do futebol que, por sua vez, já fervia no sangue popular, aproveitando-se do apoio à prática dado por diversos empresários, como que o usurpando de uma política regional, o que significa dizer que, ao procurar controlar a vida operária, Getúlio Vargas incorporou o que os trabalhadores já carregavam no seu cotidiano, apenas projetando essa modalidade esportiva em termos nacionais, fortalecendo, dessa forma, elos, em especial a partir dos eventos mundiais denominados Copas do Mundo.

Isto significa dizer que foi com Getúlio que a febre futebolística, que tomou os brasileiros durante as duas primeiras décadas do século, foi absorvida como um dos símbolos que poderiam constituir no país determinado sentimento nacionalista. Porém, as ações de Vargas ficaram vinculadas substancialmente às Copas do Mundo, embora o apoio a agremiações de sustentação às suas intenções não devam ser desconsideradas. E quem a ele sucedeu no comando das rédeas do país, idem, uma vez que as particularidades das ações ficaram em esfera local, o que significa dizer que se a estrutura montada pelos clubes deu a Vargas a base para uma política nacional e a projeção do esporte teve como devolutiva a afirmação de poderes regionais mais consistentes

No Brasil, o futebol teria sido edificado como tradição com a intenção de criar uma amálgama entre os brasileiros, principalmente a partir da profissionalização do esporte, em 1933, e das intenções integradoras de Getúlio Vargas, a partir de 1937, embora Luiz Carlos Ribeiro advirta que a paixão do brasileiro pelo esporte não pode ser simplificado a uma vontade política de Vargas ou aos textos apaixonados divulgados pela mídia que teriam ancorado seus projetos à emoção de torcer (RIBEIRO, 2012, p.34). Neste sentido, é importante que se reflita sobre o papel da imprensa esportiva na formação da identidade nacional e na construção da memória através do resgate de imagens, fatos, êxitos e fracassos, além da estruturação do futebol enquanto espetáculo captador de bons negócios. A ação da imprensa esportiva formou (e continua a formar) tradições através de apropriações do passado. Neste sentido, destaque à figura de Mário Filho. 
Durante o Estado Novo (1937-1945), particularmente após a boa campanha da seleção brasileira na Copa de 1938, Getúlio Vargas procurou concretizar seu projeto de dar ao Brasil um sentido de nação ordenada com o futebol. Para tanto, utilizou-se da mídia, apresentando nos jornais uma massa torcedora como um conjunto harmônico, coletivo e disciplinado e procurando, desta forma, consolidar o futebol como um esporte nacional ao desconstruir o espírito individualista e libertário do jogador brasileiro. Mesmo Leônidas da Silva - o grande craque brasileiro à época - teve sua imagem de irreverência substituída pelo estadonovismo, passando a ser apresentado como um homem cordial e unificador. Desta forma, o destaque adquirido por Leônidas teria contribuído para a compreensão da construção simbólica da ideia de nação através do futebol idealizada durante o Estado Novo.

A partir do torneio de 1938 a identidade brasileira encontrou nas Copas do Mundo seu ritual de congregação máximo já que, por ocasião do evento, valores sociais passaram a ser compartilhados entre os brasileiros, fazendo florescer um nacionalismo nem sempre presente na vida diária nacional, sempre com reforço da mídia e das campanhas publicitárias, fazendo com que a seleção do país passasse a ser vista com representante de toda uma coletividade.

A partir da participação brasileira na Copa de 1938, servir ao país através do futebol virou tarefa obrigatória. Ou seja, negar uma convocação para uma seleção como a brasileira seria uma recusa de se servir à nação; ato faria o jogador sofrer punições simbólicas da sociedade.

Sim, o futebol foi utilizado pelo Estado como instrumento para se criar um sentimento nacionalista entre brasileiros, o que, aos olhos de Eric Hobsbawm, é visto com naturalidade, afinal para este historiador, "a imaginária comunidade de milhões parece mais real na forma de um time de onze pessoas com nome" (HOBSBAWN, 1990, p. 171).

Dentro do imaginário político nacional, a partir das atenções dadas por Getúlio Vargas, talvez o futebol tenha passado a ser o traço cultural mais relevante na representação da cultura política brasileira. Desta forma, entender a trajetória do "jogo da bola" é entender um pouco mais do Brasil, de sua história e de sua gente. Um esporte que, a princípio, associou-se às elites e que se popularizou de forma assustadora, em especial a partir do primeiro quartel do século XX, período em que as agitações operárias preocupavam proprietários e governo (este último enquanto representante dos interesses dos possuidores e do Estado em si): "Tudo somado - massa, cumplicidade, compromisso, heroísmo -, gera-se a euforia que domina o futebol e o torna um poderoso instrumento social, que está à disposição de variados interesses, dentre os quais o do Estado (GUTERMAN, 2006, p. 20). Getúlio e o Estado Novo, desta forma, teriam alcançado - se não no todo, ao menos em boa parte - seus objetivos integradores. 
Seja como for, os caminhos e a trajetória do futebol na História brasileira deixaram legados e está em nosso cotidiano. Talvez não tenha criado o tão sonhado sentimento nacionalista pretendido por Vargas, mas colaborou para espasmos de sentimentos de brasilidade como os temos na contemporaneidade, isso porque, mais do que um país, talvez o Brasil seja um amontoado de pátrias (no sentido de lugar em que se nasce). A identificação com o regional - em que pese os esforços de Getúlio Vargas - é maior que com o nacional, com o todo. Um país de pátrias instituídas como refúgio. O próprio clube pelo qual se torce seria uma pátria em que o brasileiro procura abrigo, conforto e razão para existência. Servindo ou não a propósitos, talvez Wisnik (2008, p. 11) tenha razão ao afirmar que "viver o futebol dispensa pensá-lo, e, em grande parte, é essa dispensa que se procura nele".

\section{Referências bibliográficas}

ALABARCES, Pablo. Fútbol y pátria: el fútbol y las narrativas de la nación em la Argentina. Buenos Aires: Prometeo Libros Editorial, 2002.

BOMENY, Helena M. B. Três decretos e um ministério: a propósito da Educação no Estado Novo. In: PANDOLFI, Dulce (Org.) Repensando o Estado Novo. Rio de Janeiro: Fundação Getúlio Vargas, 1999.

CABRAL, Cid Pinheiro. História do Mundial de Futebol. São Leopoldo: Andreas Stihl, 1978. CARONE, Edgar. O estado novo (1937-1945). São Paulo: Difel, 1977.

CORREIO DA MANHÃ, 08 de Junho de 1938.

COSTA, Maurício da Silva Drumond. Os Gramados do Catete: futebol e política na era Vargas (1930-1945). In: SILVA, Francisco Carlos Teixeira da \& SANTOS, Ricardo Pinto dos (orgs.). Memória Social dos Esportes- Futebol e Política: a construção de uma identidade nacional. Rio de Janeiro, Mauad Editora: FAPERJ, 2006.

COUTO, Euclides de Freitas. Da ditadura à ditadura - uma história política do futebol brasileiro. Rio de Janeiro: Eduff, 2014.

DIÁRIO S. PAULO, 29 de maio de 1934.

FRANCO JR, Hilário. A Dança dos Deuses: futebol, sociedade, cultura. SP: Companhia das Letras, 2007.

GOMES, Ângela de Castro. Regionalismo e centralização política: partidos e constituinte nos anos 30. Rio de Janeiro: Nova Fronteira, 1980.

GOMES, Ângela de Castro. O populismo e as ciências sociais: notas sobre a trajetória de um conceito. In: FERREIRA, Jorge (Org.). O populismo e sua história: debate e crítica. Rio de Janeiro: Civilização Brasileira, 2001.

GUTERMAN, Marcos. O Futebol Explica o Brasil. Tese de Mestrado, São Paulo. PUC, 2006. HOBSBAWM, Eric. Nações e nacionalismo. Rio de Janeiro: Paz e Terra, 1990.

O ESTADO DE S. PAULO, 07 de fevereiro de 1937; 02 de fevereiro de 1938; 21 de abril de 1938; 21 de abril de 1938; 11 de junho de 1938.

JORNAL A GAZETA, 06 de abril de 1938.

JORNAL A NOITE, 06 de maio de 1938.

JORNAL DOS SPORTS, 02 de fevereiro de 1937; 16 de março de 1938; 21 de março de 1938. KUPPER, Agnaldo. Nos rastros da bola: o futebol brasileiro entre apropriações e desapropriações. Tese de Doutorado. Universidade Estadual Paulista, 2019. 
LYRA FILHO, João Lyra. Raça, educação e desporto. Estudos e Conferências. Rio de Janeiro: DIP, n. 14. 1941.

MOSCOVICI, Serg. Representações sociais: investigações em psicologia social. Trad. Pedrinho A. Guareschi. Petrópolis: Vozes, 2012, 9 ed.

NEGREIROS, Plínio J. L. de C., in Márcia Regina Costa (org.). Futebol: o espetáculo do século. SP: Musa, 1979.

NEGREIROS, Plínio J. L. de C. Futebol e identidade nacional: o caso da Copa de 1938. Coletânea do V Encontro de História do Esporte, lazer e Educação Física. Editora Unijuí, 1997. PARDINI, Melina Nóbrega Miranda. A narrativa da Ordem e a Voz da Multidão: Futebol na Imprensa durante o Estado Novo. Tese, Universidade de São Paulo, 2009.

RIBEIRO, Luiz Carlos. Futebol: por uma história política da paixão nacional. Revista História: Questões \& Debates. Curitiba: Edit. UFPR, n. 57, 2012.

RIGAUER, Bero. Sport und Arbeit. [S. l.: s. n.], 1969.

SOUZA, Denaldo A. O Brasil entra em campo: estado, trabalhadores e imprensa na construção da identidade nacional através do futebol (1930-1947). Dissertação de Mestrado, 2002. UFF, Niterói.

SOUZA, Glauco José Costa. O futebol nós podemos jogar: uma análise sobre o desenvolvimento do futebol fora dos clubes da elite do Rio de Janeiro. Revista Recorde, Rio de Janeiro, v. 8, p. 46, 2015.

VARGAS, Getúlio. Diário. São Paulo: Siciliano; Rio de Janeiro: Fundação Getúlio Vargas, 1995.

WISNIK, José Miguel. Veneno remédio: o futebol e o Brasil. São Paulo: Cia das Letras, 2008. 